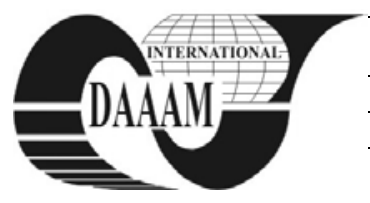

\title{
MAINTENANCE-RELIABILITY DUALITY FOR A 40 BARS COMPRESSOR FROM A PET BOTTLING LINE
}

\author{
BIBIRE, L[uminita]; GHENADI, A[drian] S[telian] \& TOPLICEANU, L[iliana]
}

\begin{abstract}
Correctly maintained equipments can give good results at work. Work breaks to remedy defects due to bad maintenance overlapping repairs costs are more expensive than the maintenance work carried out carefully. Paper analyzes maintenance-reliability duality for a 40 bars compressor from a PET Bottling Line, of manufacture 2007. Analyzing of defects graphs for 2008, 2009 and 2010, led to conclusions concerning on the sensible locations and the reasons of damage for each element. Depending on the type of defects, corrective measures are taken for them, and prevention measures are taken, too, in the future.
\end{abstract}

Key words: maintenance, reliability, predictive maintenance, compressor

\section{INTRODUCTION}

Although the concept of reliability is very old (it appeared simultaneously with the technique), it was constituted as theory in recent decades and it is in a continuous development. Old concept and new discipline, reliability theory is an interdisciplinary science which refers to a large number of problems on all stages of life products (design, manufacturing, transportation, installation, operation, decommissioning, etc (Titu, 2008).

Notion of reliability has emerged around 1960, being detached from the concept of quality, the term representing the ability to maintain product quality throughout its specified use (Teodorescu, 2008).

Reliability is maintained by using appropriate methods of conservation, transport, commissioning and operation (Teodorescu, 2008).

The subject of reliability is:

- defects study (causes, occurrence and development processes, methods of combat);

- quantitative assessment of behavior products in time, as a function of internal and external influence factors (Teodorescu, 2008).

Generally, failure effects of an element have consequences infinitely greater than the cost of element (Carnero, 2006).

Presently, reliability study of a technical system, involves the maintenance concept (maintainability). This concept is defined in the literature in various ways. All of them do however references to systems ability, expressed qualitatively or quantitatively to be repaired and to be put back into operation, in case of failure, through the maintenance actions (Titu, 2008).

Reliability Centered Maintenance RCM has target optimal equipment reliability (Carnero, 2005).

Failure modes, detailed understanding of how the equipment failure and its consequences are very important (Teodorescu, 2008).

Because, the most of the times, the "failures" are more expensive than the costs of "maintenance", the efforts to analyze the failures are very effective, when preventive measures or corrective actions are taken. In the first year of operation it is very important to know the location of failures for increased effectiveness of intervention (Wenzhu et al., 2010).

For each type of equipment, sensible locations may be different. It is important to know the reasons of damage for each element.

\section{IDENTIFICATION OF 40 BARS COMPRESSOR IN BOTTLING INSTALLATION}

Analyzed 40 bars compressor is part of a PET bottling line manufactured in 2007. Bottling line consists of the following equipment, with the following input parameters:

- 40 bars compressor;

- $\quad$ sorting installation;

- formming machine though blowing compressed air min 36 bars;

- $\quad$ operating air - min 6 bars;

- pneumatic transporter;

- $\quad$ rinsing machine - min 1.5 bars;

- $\quad$ machine for operational air bottling - min 5.5 bars;

- $\quad$ water- min 1.5 bars; $\mathrm{CO}_{2}$ - min 4 bars;

- cold filtration system (CFS), operational air - min 5.5 bars; $\mathrm{CO}_{2}=5$ bars;

- control equipment;

- conveyor and agglomeration belts;

- $\quad$ labeling machine, operational air - min 5 bars; water min 1.5 bars,

- date inscription installation;

- $\quad$ wrapping boxes machine;

- $\quad$ handles applied machine, operational air - min 3.5 bars;

- $\quad$ palletised machine, operational air $=\min 5$ bars;

- $\quad$ pallets wrapping machine; operational air - min 5 bars;

- installation to apply barcodes on pallets.

High-pressure compressor for producing 40 bars compressed air is shown in figure 1. Produced compressed air is stored in a buffer tank, from where it is sent to the condens separation and then to the formed machine by blowing.

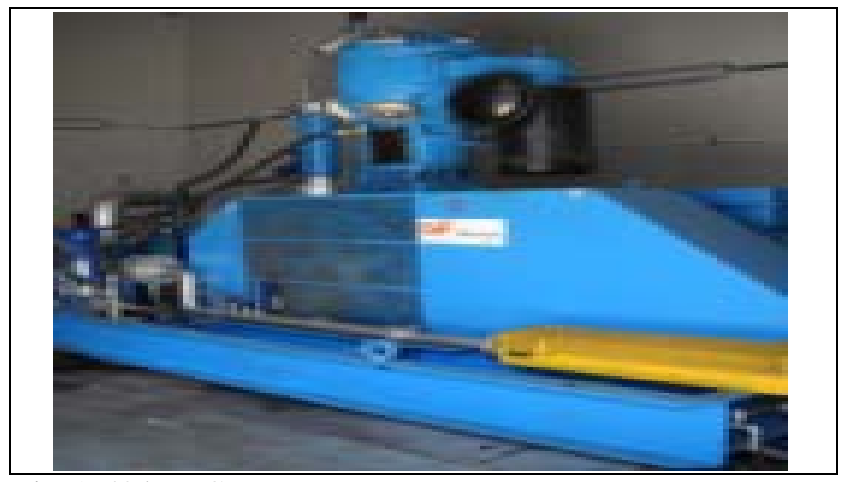

Fig. 1.40 bars Compressor 


\section{ASPECTS REGARDING THE BOTTLING LINE MAINTENANCE}

Failure to specifications required by the manufacturer, leads to frequent interruptions due to malfunctions, premature failure of components, huge costs to repair malfunctions, shorter life time for equipment. Analyzed bottling line is part of endowment brewery from Romania. Because it is used in the food industry, required current maintenance works, are: preliminary cleaning, care and maintenance, lubrication works, re-equipment, main cleaning, repairs/maintenance works/preventive maintenance/revisions, which must be made mandatory during cleaning and disinfection activities, or after.

The works are ordered by size execution intervals. Works at longer intervals include works of shorter intervals. For example, the maintenance of the factory which has a same bottling line, includes current revisions. Thus, for an interval of weekly work or for each 50 operation hours, current revision intervals are twice per week. Another option exists: for every 25 operation hours, revision to be make daily, or at every 10 operation hours.

All defects are listed in the defects register of industrial unit which includes bottling line. For analyzed bottling line, an report regarding the defects number of the bottling line shall be prepared, monthly, for each machine separately. Depending on the type of defects, corrective measures are taken for them, and in the future prevention measures are taken.

Also preventive maintenance activities are carried, such as equipments and some components are checked at risk of failure, and if certain deficiencies or defects are found, targeted parts will be replaced. Thus, damage and their remedy during production are avoided.

\section{STUDY ON MAINTENANCE OF 40 BAR COMPRESSOR}

According to malfunctions registers, graphic both for mechanical and electrical defects can be traced, for each year separately, depending on equipment. Thus, in Figure 2, defects of 40 bar compressor for 2008, 2009, 2010, are presented.

\section{CONCLUSIONS REGARDING THE RELIABILITY CENTERED ON THE MAINTENANCE AT 40 BARS COMPRESSOR}

After graphs analyzing for 2008, 2009 and 2010, we can say that some damage occurs mainly in certain months of the year.

We can also notice that defects number begin to decrease over time. Considering that compressor, like all machines of bottling line, are new, a higher rate of defects during the first months of 2008 is observed. Comparing defects for each year from the putting into operation of the bottling line, it can easily notice a decrease of failure rate.

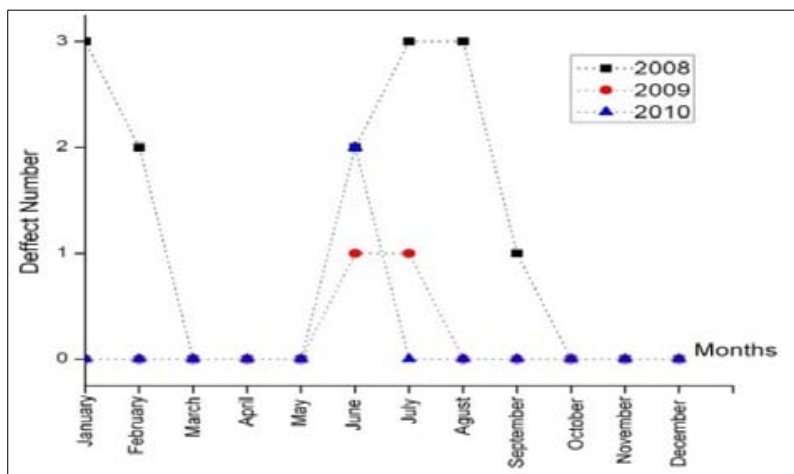

Fig. 2. Defects of 40 bars compressor for 2008, 2009, 2010
Watching graphics which represents defects throughout the operation, for 40 bars compressor from bottling line, we can see that during the first period of operation life, defects are more frequently. This fact is due to manufacturing defects, hidden defects.

According to registers of damage, the most frequently defects are found at electrical and electronic parts, such as: optical sensors, inductive sensors, electro-magnetic sensors, frequency converters, input-output signal modules, memory cards, software errors, programming errors, engines.

Analyzing reliability of 40 bars compressor, in terms of maintenance program of the bottling line, it is found that weaknesses were to:

- $\quad$ cooling water thermostat malfunction;

- cooling water manometer malfunction;

- final heat exchanger malfunction;

- cooling water filter malfunction;

- belt malfunction;

- $\quad$ oil bath thermostat malfunction;

- admission-evacuation valves malfunction;

- $\quad$ overpressure valve malfunction.

Most damage occurred during the grinding line.

It is noted very well that defects had the highest rate in January, February and March, 2008. This is due to initial start into operation, following that in coming months failure rate to decrease.

As it can see, defects are becoming fewer over time. For example, if in 2008 we had a total of 14 defects, in 2009 these decreased to 3 defects, and during the first half of 2010 only 2 defects were, below the defects average of the first 6 months versus the years 2008 and 2009.

Reducing maintenance costs is possible by:

- implementation of an suitable organization;

- achievement of an optimal monitoring;

- especially externalization of some maintenance activities;

It is necessary that those measures to be associated with elements of improving safety during operation, using technologies/advanced knowledge.

\section{ACKNOWLEDGEMENTS}

I want to thank to eng. Bogdan Oprea for his support given to me in achievement of the study case

\section{REFERENCES}

Carnero, M. C. (2005). Selection of diagnostic techniques and instrumentation in a predictive maintenance program. A case study. Decision Support Systems 38(4): 539-555, Availablefrom:

http://www.sciencedirect.com/science/article/pii/S0167923 603001283/ Accessed: 2011.04.07

Carnero, M. (2006). An evaluation system of the setting up of predictive maintenance programmes, Reliability Engineering \& System Safety Vol. 91, Issue 8 (August, 2006), pages number: 945-963. ISSN: 0951-8320

Teodorescu, N., (2008), Mentenanta generala in domeniul ingineriei mecanice, Editura AGIR, ISBN 978-973-720180-5, Bucuresti

Titu, M., (2008), Fiabilitate si mentenanta, Editura AGIR, ISBN 978-973-720-169-0, Bucuresti

Wenzhu L., Ershun P., Lifeng X., (2010), Preventive maintenance scheduling for repairable system with deterioration, Journal of Intelligent Manufacturing Vol. 21, Issue 6, pages number: 875-884, ISSN: 1572-8145 (electronic version) 